\title{
Notes on the vocalizations of Thick-billed Flowerpecker (Dicaeum agile)
}

Peter Boesman

In the following we briefly analyze and compare voice of the different races of Thick-billed Flowerpecker (Dicaeum agile). We also try to quantify the extent of any vocal differences using the criteria proposed by Tobias et al. (2010), as a support for taxonomic review.

We have made use of sound recordings available on-line from Xeno Canto (XC) and Macaulay Library (ML).

An overview of vocalizations per group:

Nominate group (agile/zeylonicum)

Commonly heard voice is a sharp "spick". Also a fast series of higher-pitched notes (presumed song), a chattered series of more raspy short notes, and slightly longer highpitched notes.

Presumed song:

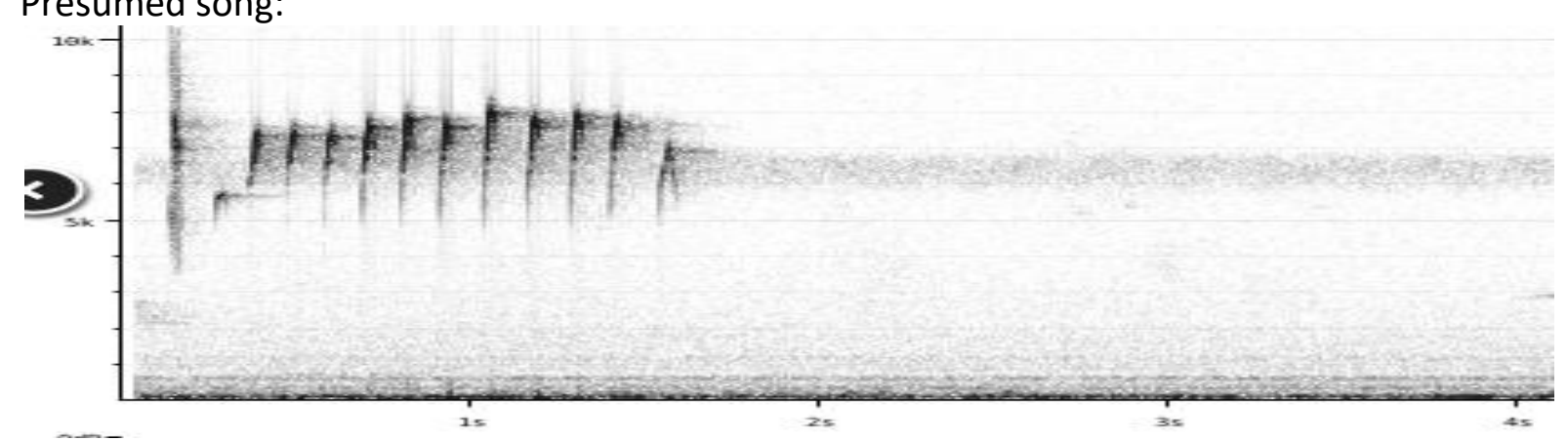

"spick" call note:

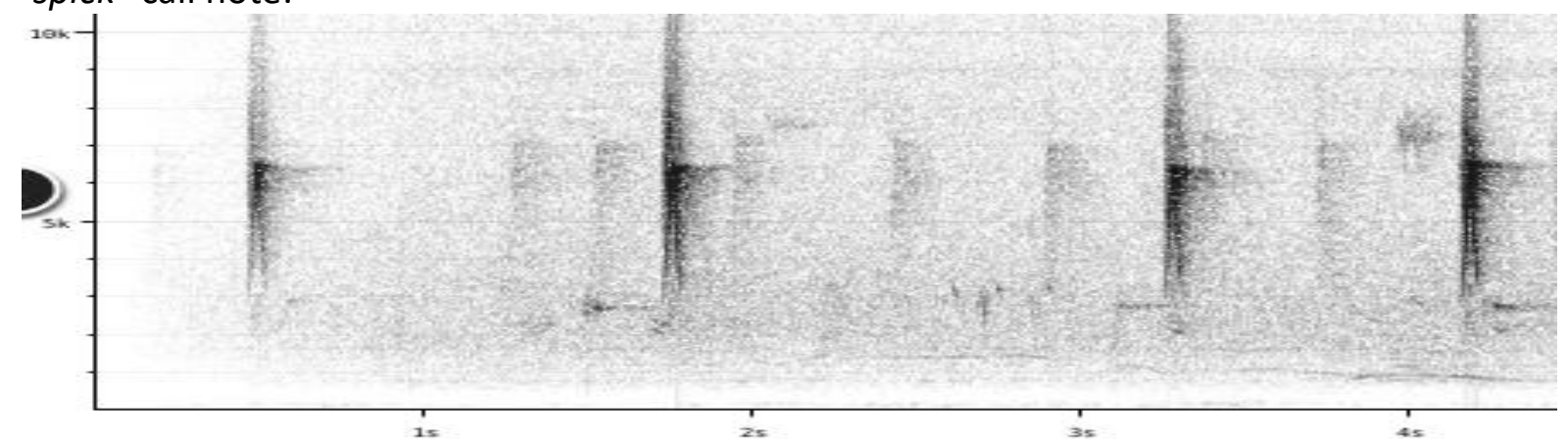

"spick" and chatter:

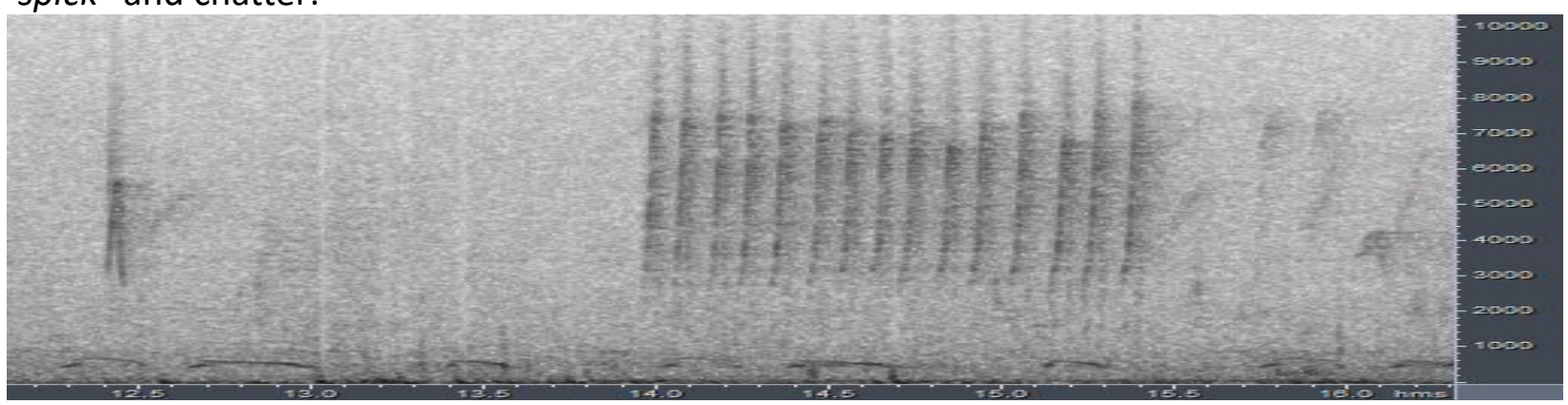




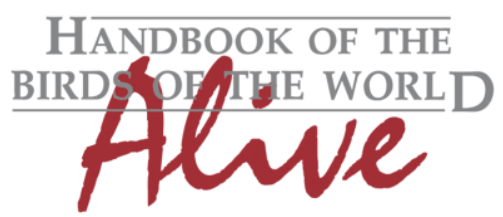

\section{ORNITHOLOGICAL NOTES}

"spick" and longer high-pitched notes:

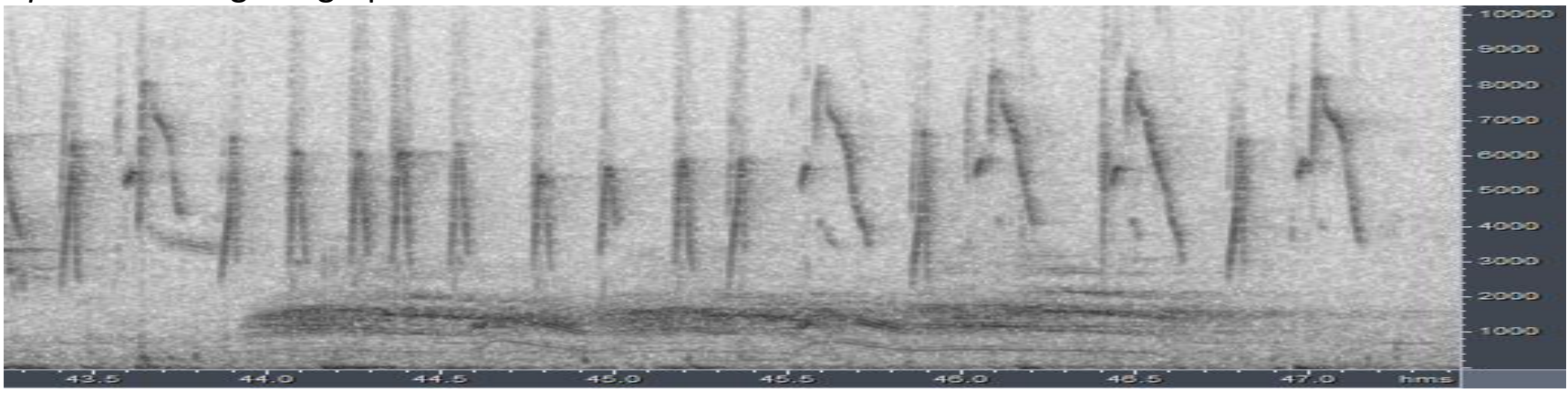

SE Asia group (pallescens, modestum, obsoletum a.o.)

Vocalisations include chattered series of short raspy notes, and high-pitched notes, and seemingly also a fast series of higher-pitched notes (presumed song, very similar to previous group). Only the "spick" call of previous group apparently has not been recorded (yet).

Presumed song:
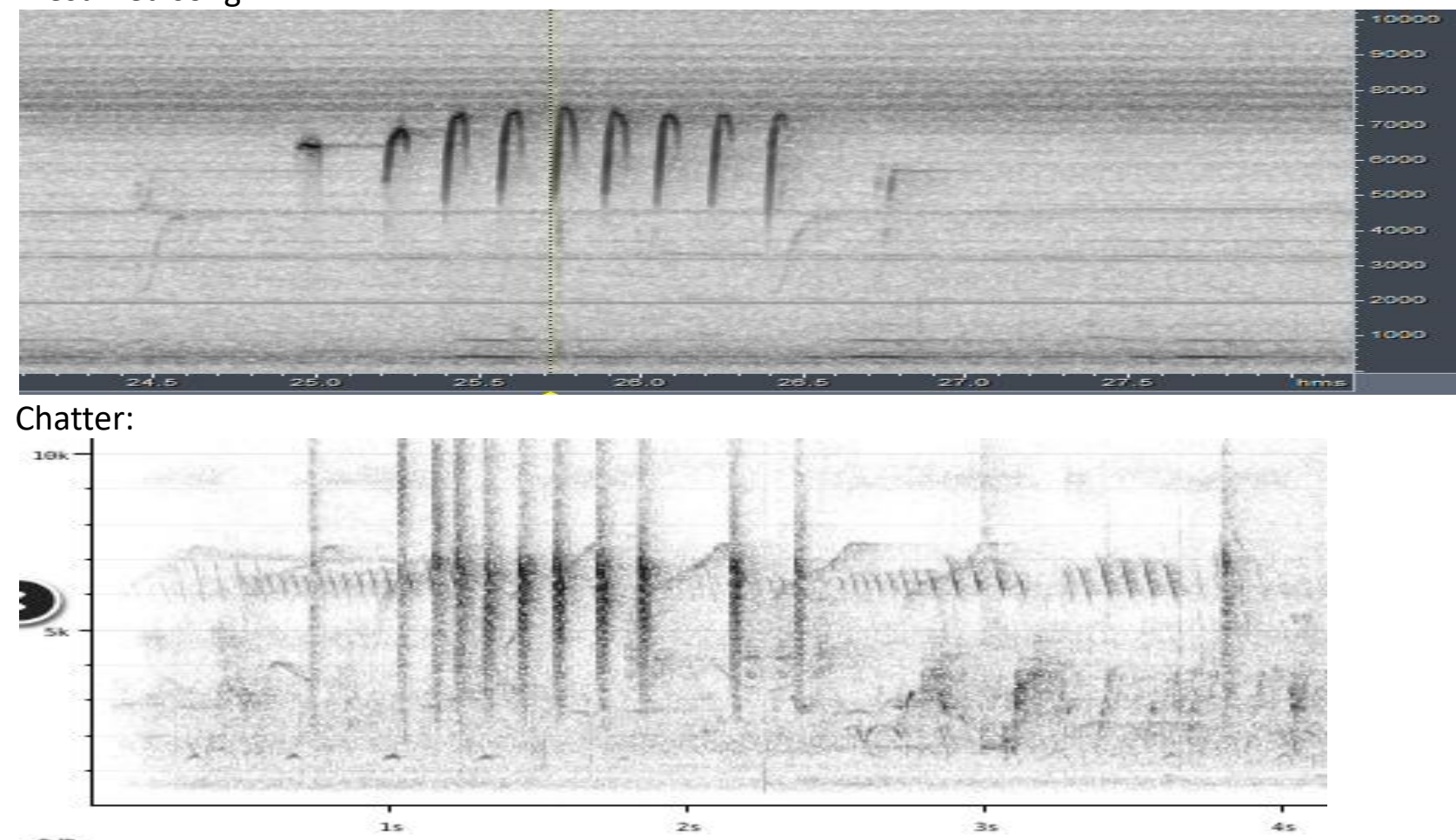

Longer high-pitched notes:

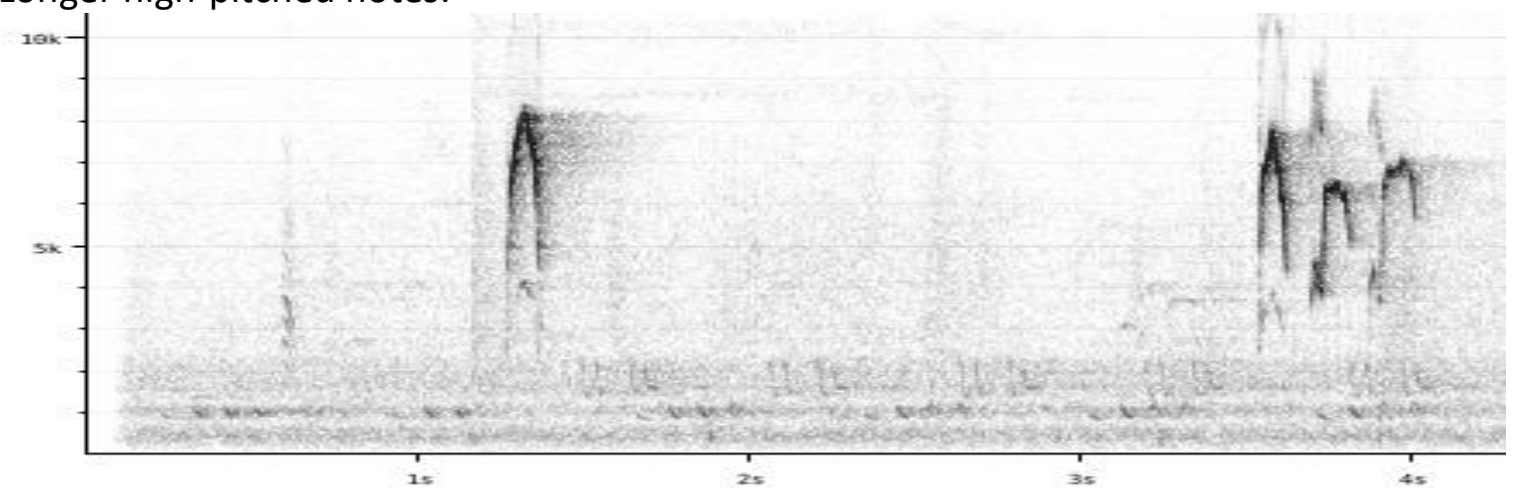



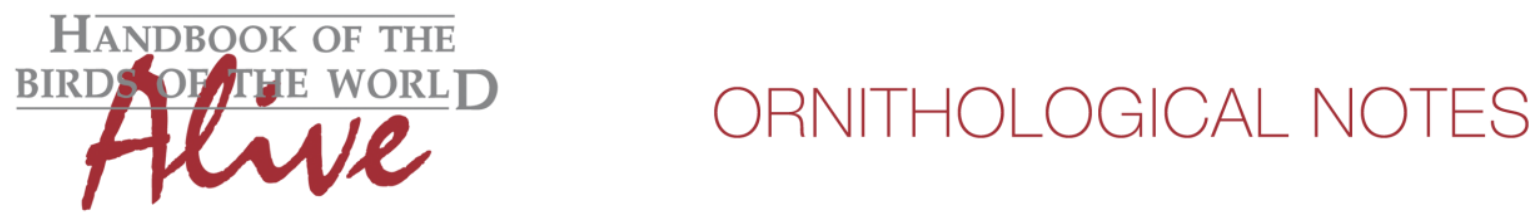

\section{Philippine group}

We have found only 2 recordings, of the 'single, high-pitched note' type and possibly also a "spick" call (sonogram 2).

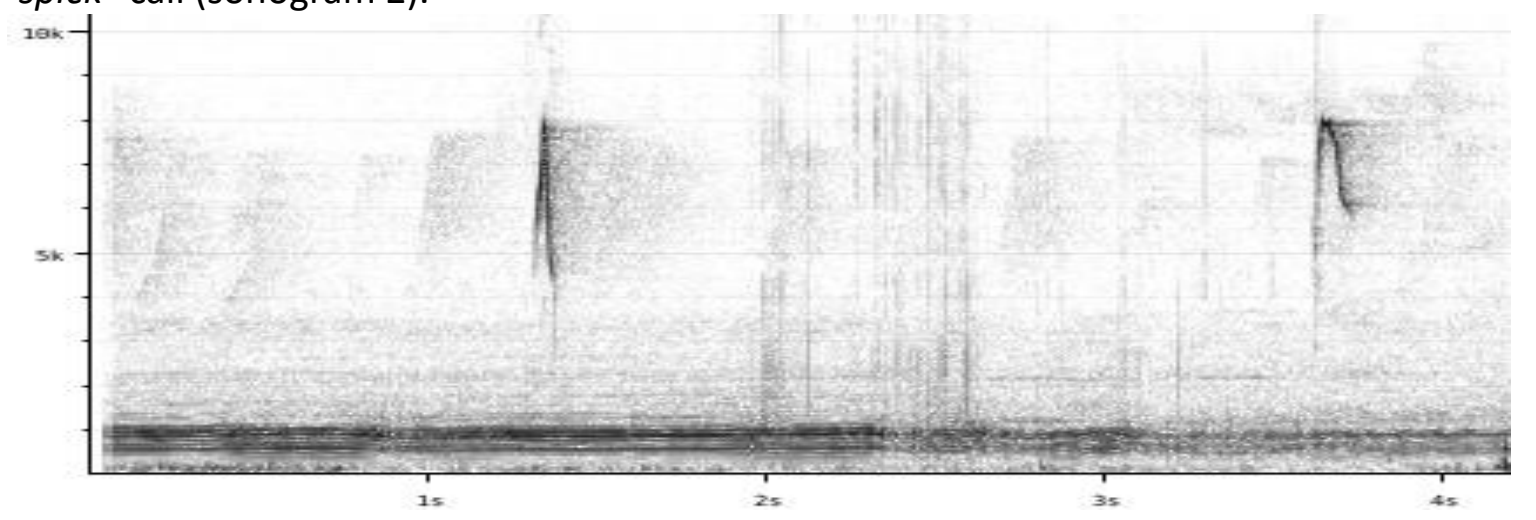

"spick" and longer high-pitched notes

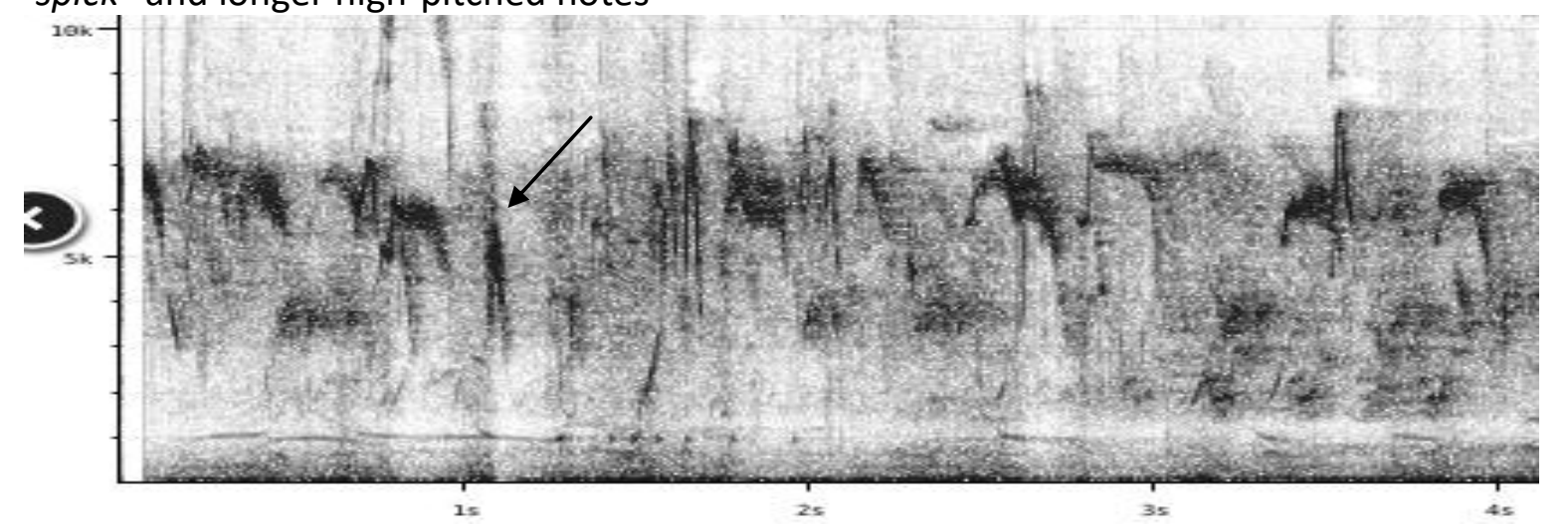

There are only a few recordings available of the SE Asia and Philippine group, and thus it is likely that vocal repertoire is more extensive than what can be deducted from the recordings. Nevertheless, it is quite clear that all groups share several vocalizations types.

With the above evidence, we can only conclude that there is not a strong indication of vocal difference. At most, we can conclude that the sharp "spick" call (reaching c. 6kHz) has not been recorded in the SE Asian group, and furthermore there are some minor differences in note shapes.

More recordings are needed to allow for a more in depth analysis.

The SE Asia group has been split from nominate Indian group, partly based on vocal differences (Rasmussen \& Anderton 2012), but this is seemingly based on a single recording of SE Asia group, failing to document the entire vocabulary of this group.

This note was finalized on 23rd June 2016, using sound recordings available on-line at that moment. We would like to thank in particular the sound recordists who placed their recordings for this species on XC and ML: Patrik Åberg, Desmond Allen, Marc Anderson, Greg Budney, David Farrow, Vir Joshi, ben King, Albert Lastukhin, Petter Olsson, Rajgopal Patil, Craig Robson and Arnoud Van den Berg. 


\section{References}

Rasmussen, P.C. \& Anderton, J.C. (2012). Birds of South Asia: the Ripley Guide. Vols. 1-2. 2nd edition. National Museum of Natural History, Smithsonian Institution, Michigan State University \& Lynx Edicions, Washington, D.C., Michigan \& Barcelona.

Tobias, J.A., Seddon, N., Spottiswoode, C.N., Pilgrim, J.D., Fishpool, L.D.C. \& Collar, N.J. (2010). Quantitative criteria for species delimitation. Ibis 152(4): 724-746.

\section{Recommended citation}

Boesman, P. (2016). Notes on the vocalizations of Thick-billed Flowerpecker (Dicaeum agile). HBW Alive Ornithological Note 333. In: Handbook of the Birds of the World Alive. Lynx Edicions, Barcelona. (retrieved from http://www.hbw.com/node/1252792 on 24 October 2016). 